\title{
A Novel Fuzzy Approach to Gas Pipeline Risk Assessment Under Influence of Ground Movement
}

\section{Agnieszka Malinowska ( $\nabla$ amalin@agh.edu.pl)}

AGH University of Science and Technology: Akademia Gorniczo-Hutnicza imienia Stanislawa Staszica w Krakowie https://orcid.org/0000-0002-8492-9073

\section{Ximin Cui}

CUMT - Beijing Campus: China University of Mining and Technology - Beijing Campus

\section{Ebrahim Fathi Salmi}

UTAS MRIT: University of Tasmania Menzies Institute for Medical Research

\section{Ryszard Hejmanowski}

AGH University of Science and Technology: Akademia Gorniczo-Hutnicza imienia Stanislawa Staszica w Krakowie

\section{Research Article}

Keywords: gas pipeline, risk management, land subsidence, horizontal strains, fuzzy logic, GIS

Posted Date: October 13th, 2021

DOl: https://doi.org/10.21203/rs.3.rs-929951/v1

License: (c) (i) This work is licensed under a Creative Commons Attribution 4.0 International License.

Read Full License 


\section{Abstract}

The gas transport infrastructure is frequently localized in areas subjected to anthropogenic movements and strains. The potential impact of such deformations on the gas pipeline in the aspect of its damaging can be properly assessed by, e.g. by predicting strains, taking into account the causes of terrain movement. On the other hand the hazard is also related to technological factors like design of the pipeline. The presented method is based on artificial intelligence methods allowing for evaluation of probability of failure risk in gas supply pipeline sections. The Mamdani fuzzy inference was used in the study. Uncertainty of variables characterizing the resistance of the gas pipeline and predicted continuous deformations of ground surface were accounted for in the model by using triangular-shaped membership functions. Based on the surface deformations and gas pipeline resistance and the inference model one can make prediction when the gas pipeline is hazarded. The proposed model can contribute to the protection, cost optimization of the designed pipelines and to the repairs of the existing gas pipelines

Trial registration number and date of registration: COAL-D-21-00255, 27.09.2021

\section{Highlights}

- Establishment of risk of failure occurrence in gas supply system.

- Fuzzy description of risk factors.

- Risk factors: ground horizontal strains, pipes strength, duration of negative impact.

- Mamdani- type fuzzy model provides a gas pipeline failure probability map.

- Presented approach succeeds to support gas pipeline management.

\section{Statement Of Novelty}

A novel approach to risk assessment of the failure occurrence in gas supply system was presented in the article.

world's research works on pipelines in unstable areas are mainly solved with analytical or numerical methods. However, expert and fuzzy methods for pipeline risk evaluation have recently gained in popularity. Presented approach is based on fuzzy logic that enables dealing with uncertainties related to possible ground horizontal strains, the strength of the pipeline material and, the duration of negative impact. Presented analytic approach based on fuzzy logic provides a map with dynamic probability of failure of gas pipelines.

\section{Introduction}

The protection of the existing objects and technical infrastructure in the mining areas is one of the world's mining problems. The cost of the protection and maintenance cost of the existing water and gas supply networks, frequently not adjusted to the mining impact, is very high (Supreme Audit Office, 2012). The 
cost of replacement and fixing of old gas and water supply networks may amount up to $80 \%$ of all costs of the mining-induced damage. Therefore in the case of newly built objects, the mining entrepreneurs try to maintain safety of these objects and of the technical infrastructure. When a high pressure gas supply pipeline is involved, its correct functioning is also connected with the public safety. The Regulation of the Minister of Economy (Official Journal of 26 April 2013) defines the conditions which should be met when designing and building gas supply networks. These are, among others, geologic, hydrogeological conditions as well as requirements relating to the protection of the environment and historical monuments. 'Gas supply networks should be designed and built in compliance with the construction law in a way which provides its safe exploitation and supplies of gaseous fuel'.

In areas where surface deformations may be expected, gas pipelines are designed with the use of models illustrating the interaction of a gas supply pipeline with unstable ground, based on statistical and strength calculations (Broniec et al. 1998, Hotloś\&Mielcarzewicz 2011, Jachym\&Kalisz 2010, Kopczyński 1991, PN-90/M-34502). Calculations are conducted for particular elements of the gas supply pipeline and allow for determining the strain distribution in the pipeline cross-sections. They also allow for determining axial strains in the gas pipeline axis, even the planned distance between compensators. These calculations are based on the results of predictions of expected surface deformations. The resistance of the planned object (its linear sections) to the impact of surface deformations in the moment it is construction, is calculated on the basis of statistical-strength calculations. These calculations hold true for time-dependent extreme surface deformations. This means that the deformations which are extreme in time are determined for the duration of the concession (e.g. 50 years). The static strength calculations are conducted for the maximum value of horizontal strains, which will appear under the object. The predictions neither account for the time interval in which biggest strains appear under the gas pipeline, nor the construction complexity of the object. The prediction of continuous ground deformations and evaluation of resistance of linear objects is burdened with considerable uncertainty resulting from inaccuracy of modelled data. These are mining and geological data on the basis of which continuous deformations are modeled, and information about the design of the object,

-limitations of prognostic models, which give only approximated description of the strain and subsoil/object interaction,

-subjective evaluation of experts evaluating the resistance of the existing object.

This has recently increased the popularity of expert, multicriteria and fuzzy methods of pipeline hazard evaluation (Brito\&de Almeida 2009, Cango et al. 2000, Esayed 2009, Han\&Weng 2011, Hu et al. 2013, Hu et al. 2016, Markowski\&Mannan 2009, Shahriar et al. 2012, Qu et al. 2016). These methods may incorporate more variables which cannot be directly modeled in the water network hazard modeling. These are quantitatively unmeasurable data, e.g. corrosion and technical condition (Jamshidi et al. 2013, Linlin et al. 2015, Malinowska\&Hejmanowski 2015, Singh\&Markeset 2009, Singh\&Markeset 2014). Moreover, expert evaluation (burdened with uncertainty) can be also modeled in the context of potential damage of gas pipelines. The result of hazard modelling can have numerical and also linguistic 
character. This is especially important when the predictions are performed for state institutions or inhabitants of areas hazarded with gas pipeline failures (Singh\&Markeset 2009). The suggested solutions prove the applicability of fuzzy inference method for assessing gas network hazards. The notion of risk is introduced in the sense of a financial loss and risk management. The protection of gas supply networks considerably goes beyond statistical and strength analyses on behalf of analyses taking into account evaluation of quantitative and qualitative variables and uncertainty factor (Mokhtari et al., 2011).

The problem of correct evaluation of hazard of gas supply pipelines in mining-induced areas is not the only key element of maintaining safety in strongly urbanized areas. The present approach, based on statistical and strength analyses, did not account for the dynamics of development of deformation fields, qualitative changes (technical condition) and uncertainty resulting from the modeling and determining variables. There was no available method which would support the risk management of the water supply network failure in mining areas and simultaneously account for qualitative, quantitative and uncertainty variables. A variant risk analysis was assumed for particular pipeline sections in the undertaken analyses. The following assumptions were also made (a) tensile strength depends on material of the gas pipeline (newly erected), (b) resistance defined on the basis of the point method (existing objects), (c) principal and axial strains, (d) uncertainty of data and of modeling. In this approach the real, predicted principal strains of the gas pipeline can be assessed and the result is given at scale 1 to 100. Accordingly, the boundary admissible risk can be assumed and used for design purposes (e.g. placement of compensators).

\section{Characteristic Of Research Area And Pipeline System}

The planned gas pipeline will run through the mining areas belonging to two underground copper mines. The first mine has conducted an intense copper production since 1970s. The other mine will start extraction in the 2020s. Most of the deposit has been extracted from the area in which the first part of the pipeline will be laid and only single lots will be produced. Therefore only certain parts of the gas pipeline will stay within the negative impact of the planned production (Fig. 1, zone1). The other part of the planned gas pipeline will pass through areas where no mining has been realized yet. In this zone the production is planned under the entire gas pipeline section which is located there (Fig. 1, zone 2).

A gas pipeline was designed on the basis of statistical and strength calculations, accounting for the expected surface deformations (by the year 2063) (Gazoprojekt 2016). In the preliminary technical assumptions attention was paid to the extreme (in a function of time) surface deformations. The total length of the gas pipeline passing through three provinces equaled to $114 \mathrm{~km}$. A $50 \mathrm{~km}$ pipeline section will go through the Lower Silesia Province, out of which $18615 \mathrm{~m}$ will be running through the mining areas. The planned diameter of pipes used for the gas pipeline will range from 250 to 350 DN (the pipe's wall will be 4.5 to $5.0 \mathrm{~mm}$ thick). The planned gas pipeline belongs to a group of high-pressure pipelines, where the working pressure will not exceed 6.3 $\mathrm{MPa}$. The planned strength groups of pipeline steel are: L415 MB (for DN350), L360 MB (for DN 300), L290 MB (for DN 250). 


\section{Research}

The research was divided into three basic stages. The first one was the analysis of the gas pipeline design aimed at determining pipeline's resistance to continuous deformations of the ground (3.1). A method for evaluating the resistance of the gas pipelines in areas staying under a strong negative influence of continuous ground deformations has been presented in this paper. Another stage of the prediction lied in predicting continuous surface deformations generated by the planned extraction and finding factors deciding about the hazard (3.2). The third (major) part of the research was working out a fuzzy representation of variables characterizing continuous deformations of terrain, resistance of the gas pipeline and risk of pipeline's failure (3.3). Fuzzy variables were incorporated in Mamdani inference block, on the basis of which the probability of failure occurrence in time could be determined.

\subsection{Evaluation of resistance of gas pipeline}

The resistance of a gas pipeline was defined on the basis of assumptions presented in the technical project and the approximated point method (Tables 1 and 2).

The analysis of strength parameters of materials allows for determining boundary values of horizontals deformations, which will not create hazard for the steel pipe. The boundary deformations could be described on the basis Hook's law and the tensile strength defined in laboratory conditions for each material (Table 1). The assumed average of linear elasticity for all types of steel equaled to $E \approx 2.1$ $10^{5} \mathrm{MPa}$.

Table 1. List of strength parameters for particular types of steel

\begin{tabular}{|c|c|c|c|c|c|c|}
\hline $\begin{array}{l}\text { No. of } \\
\text { material }\end{array}$ & Type & $\begin{array}{l}\text { Yield } \\
\text { point }\end{array}$ & $\begin{array}{l}\text { Tensile } \\
\text { strength }\end{array}$ & $\begin{array}{l}\text { Elongation at axial } \\
\text { disrupture }\end{array}$ & $\begin{array}{l}\text { Bending } \\
\text { testing }\end{array}$ & $\begin{array}{l}\text { Tensile } \\
\text { strength }\end{array}$ \\
\hline $\begin{array}{l}\text { EN10027- } \\
2\end{array}$ & $\begin{array}{c}\mathrm{wg} \\
\mathrm{EN}\end{array}$ & $\begin{array}{l}\mathrm{ReH} \\
\mathrm{min} \\
\mathrm{MPa}\end{array}$ & $\begin{array}{l}\mathrm{Rm} \min \\
\mathrm{MPa}\end{array}$ & $\begin{array}{l}\text { A5 } \\
\min \%\end{array}$ & $\mathrm{KV} \mathrm{J} /{ }^{\circ} \mathrm{C}$ & $\begin{array}{l}\varepsilon_{\max } \\
\mathrm{mm} / \mathrm{m}\end{array}$ \\
\hline \multicolumn{7}{|c|}{ EN 10208-2 (DIN 17172) transmission steel pipes for gas and combustible media - B class } \\
\hline 1.0429 & $\begin{array}{l}\mathrm{L} 290 \\
\mathrm{MB}\end{array}$ & $\begin{array}{l}290- \\
440\end{array}$ & 415 & 21 & 40 & 1.98 \\
\hline 1.0578 & $\begin{array}{l}\mathrm{L} 360 \\
\mathrm{MB}\end{array}$ & $\begin{array}{l}360- \\
510\end{array}$ & 460 & 20 & 40 & 2.19 \\
\hline 1.8973 & $\begin{array}{l}\mathrm{L} 415 \\
\mathrm{MB}\end{array}$ & $\begin{array}{l}415- \\
565\end{array}$ & 520 & 18 & 40 & 2.48 \\
\hline
\end{tabular}


The calculated boundary minimum value of horizontal strains for steel L290 MB equaled to $1.98 \mathrm{~mm} / \mathrm{m}$, and maximally to $2.48 \mathrm{~mm} / \mathrm{m}$.

The strength parameters have been analyzed in laboratory conditions and on this basis only the resistance of the gas pipeline sections could be defined. Attention should be paid to the fact that in the case of gas network, the linear objects are interconnected and cooperate with other elements of the installation (e.g. compensators). The evaluation of the resistance of the gas pipeline only on the basis of strength parameters gives an incomplete picture of the actual resistance of a given object to the impact of continuous surface deformations. Therefore an approximated method was worked out thanks to which the resistance of the linear technological infrastructure can be evaluated with respect to continuous surface deformations. This method was based on statistical data relating to the observed failures in networks placed in the mining areas in relation to horizontal deformations, which occurred there (Mendecet al. 1997). The strength of a gas network is evaluated on the basis of an analysis of four attributes characteristic of the object (Table 2). Each of the four attributes is ascribed one property with a point value. Finally, the resistance of a given object is evaluated from the sum of points. The presented method can be used for evaluating hazard both of newly erected objects and the already existing ones. The planned object was to be made of steel with compensation. The number of connections per 100 meters will not exceed 100, and the condition of the newly erected object will be very good (Table 2).

Table 2. Resistance classification of water supply networks - point method (Mendec et al., 1997)

\begin{tabular}{|c|c|c|c|c|c|c|}
\hline \multirow[b]{2}{*}{ 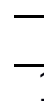 } & \multirow{5}{*}{$\begin{array}{l}\text { Risk factor } \\
\text { Material }\end{array}$} & & \multicolumn{2}{|c|}{ No. of points } \\
\hline & & \multicolumn{3}{|l|}{$\mathrm{PE}$} & \multicolumn{2}{|c|}{$0-10$} \\
\hline & & \multicolumn{3}{|c|}{ Cast iron or steel } & \multicolumn{2}{|c|}{$10-15$} \\
\hline & & \multicolumn{3}{|l|}{ PVC } & \multicolumn{2}{|c|}{$15-20$} \\
\hline & & \multicolumn{3}{|l|}{$\bar{A}$} & \multicolumn{2}{|c|}{$20-30$} \\
\hline \multirow[t]{3}{*}{2} & \multirow[t]{3}{*}{ Compensation } & \multicolumn{3}{|c|}{ Pipe socket } & \multicolumn{2}{|c|}{$0-10$} \\
\hline & & \multicolumn{3}{|c|}{ Compensators } & \multicolumn{2}{|c|}{$10-20$} \\
\hline & & \multicolumn{3}{|c|}{ No compensators } & \multicolumn{2}{|c|}{$20-30$} \\
\hline \multirow[t]{4}{*}{3} & \multirow[t]{4}{*}{ Type and number of connections } & \multicolumn{3}{|c|}{$<1$ connection $/ 100 \mathrm{~m}$} & \multicolumn{2}{|c|}{$0-10$} \\
\hline & & \multicolumn{3}{|c|}{$1-3$ connections/ $100 \mathrm{~m}$} & \multicolumn{2}{|c|}{$10-20$} \\
\hline & & \multirow{2}{*}{\multicolumn{3}{|c|}{ 3-5 connections $/ 100 \mathrm{~m}$}} & \multicolumn{2}{|c|}{$20-30$} \\
\hline & & & & $>5$ connections $/ 100 \mathrm{~m}$ & \multicolumn{2}{|c|}{$30-40$} \\
\hline \multirow[t]{4}{*}{4} & \multirow[t]{4}{*}{ Technical condition } & \multicolumn{3}{|c|}{ Very good } & \multicolumn{2}{|c|}{$0-10$} \\
\hline & & \multicolumn{3}{|l|}{ Good } & \multicolumn{2}{|c|}{$10-20$} \\
\hline & & Accep & & & & \\
\hline & & Poor & & & 30 & \\
\hline 5 & Number of points & $0-24$ & $25-48$ & $49-8$ & & $>80$ \\
\hline 6 & Resistance category & 4 & 3 & 2 & & 1 \\
\hline 7 & Admissible horizontal strain $[\mathrm{mm} / \mathrm{m}]$ & 9.0 & 6.0 & 3.0 & & 1.5 \\
\hline
\end{tabular}

The preliminary assumptions connected with planning a gas pipeline allowed for defining its resistance to the mining impact with the use of the approximated point method. Bearing in mind the material assumptions, technical condition, planned compensation and number of connections, the pipeline will be ascribed the resistance category 2 . This means that horizontal deformations up to $3.0 \mathrm{~mm} / \mathrm{m}$ do not 
represent a hazard to a given object. Ultimately the predicted horizontal strain of $3.0 \mathrm{~mm} / \mathrm{m}$ was assumed as harmfulness criterion for further analyses.

\subsection{Evaluation of hazard of terrain with continuous deformations}

Continuous deformations of surface generated by underground mining activity are predicted on the basis of stochastic or geomechanical methods. Bearing in mind the scale and complexity of the problem, the prediction of continuous deformations was performed on the basis of modified Knothe theory for copper ores (Knothe 1954). In this method continuous ground deformations can be characterized by such deformation indices as subsidence of terrain, tilt and horizontal deformations. This prognostic method has been used in many countries where surface deformations have to be predicted in areas with on-going mining extraction underground (Cui et al. 2000, Knothe 1954, Hejmanowski 2001, Malinowska\&Hejmanowski 2010, Marschalko et al. 2012).

Prerequisite investigation has reviled that domination risk factors causing failure of pipeline networks in areas subjected to significant ground deformation are (Hejmanowski et al. 2014 Malinowska \& Hejmanowski 2015, Malinowska et al. 2016):

- axial horizontal strain, $\varepsilon_{\llbracket}$, (Fig. 2),

- principal horizontal strain $\varepsilon_{\mathrm{g} 1} \varepsilon_{\mathrm{g} 2}$ (Fig. 2).

\subsection{Risk modeling for gas supply pipelines with fuzzy logic application}

The potential mining-induced risk could be determined on the basis of information about predicted continuous deformations of surface and the assumed resistance of the planned pipeline. The research was based on the fuzzy set theory (Zadeh 1965). The risk was evaluated with Mandami fuzzy model, which allows for connecting deformation risk factors with the strength of the planned pipeline in one inference block. In its original version, the model was worked out for areas staying under the influence of hard coal extraction, where the continuous deformations reached as much as $9.0 \mathrm{~mm} / \mathrm{m}$

(Malinowska\&Hejmanowski 2015). No such surface deformations have been observed in the study area, therefore the risk level is lower. On the other hand the risk level is high when we consider the significance of the object and the losses due to potential failure of the pipeline.

The first stage of fuzzy inference was determining entry and output variables of the model. Three linguistic entry variables of the model were determined.

-predicted axial horizontal strain $\varepsilon_{\square}$ (in $\mathrm{mm} / \mathrm{m}$ ),

-predicted principal horizontal strains $\varepsilon_{\mathrm{g} 1}, \varepsilon_{\mathrm{g} 2}$ (in $\mathrm{mm} / \mathrm{m}$ ),

-resistance of gas pipeline PR (defined by points ascribed to linear objects on the basis of approximated point method (Table 2). 
For the sake of defining entry variables, the risk of pipeline's failure occurrence was re-defined and expressed in point scale $\mathrm{R}$.

The second step of the research was definition of the universe of discourse and linguistic values for these variables. The predicted extreme horizontal strains were assumed to equal to $[0,9] \mathrm{mm} / \mathrm{m}$; the resistance of the gas pipeline expressed in points (point method) could theoretically assume values from 0 to 100 points. The output variable, i.e. risk of pipeline failure occurrence, was characterized by points which may take values from 0 to 100 . Linguistic values described by triangular-shaped membership functions were defined for each of the variables (Fig. 3, Fig. 4, Fig. 5) .

Four linguistic values were defined for surface deformations (axial and principal) of terrain:

$\varepsilon_{\square} / \varepsilon_{\mathrm{g} 1}, \varepsilon_{\mathrm{g} 2}=\{V L$ (Very low), L (Low), $M$ (Medium), H(High) $\}$

The resistance of the gas pipeline was also described by four linguistic values:

$\mathrm{PR}=\{$ VL (Very low), L (Low), M (Medium), $H($ High $)\}$

The risk of pipeline failure occurrence was described by four triangular-shaped membership functions defined by the following linguistic values:

$\mathrm{R}=\{L($ Very low), $M$ (Medium), $H($ High), $\mathrm{VH}($ Very high $)\}$

The third and the most important stage in the fuzzy inference modeling was the rule base creation. This is the most significant element of the fuzzy model, a core of the model. The shape of the resultant surface depends on the rules in the base. Input variables are connected in the inference block by implication rules (Table 3). Rules of if...then type allow for logical inferring: if axial strains or principal strains are high and the resistance of the pipeline is low, then the risk of failure will be very high.

The value of each linguistic value has been described by triangular-shaped membership function.

Table 3. Rule base in inference Mamdani model coupling input and output variables

\begin{tabular}{cccccc}
\hline \multicolumn{5}{c}{$\varepsilon_{\square} / \varepsilon_{\mathrm{g} 1}, \varepsilon_{\mathrm{g} 2}$} & \\
\hline PR & \multicolumn{2}{c}{ VL } & L & M & H \\
\cline { 2 - 6 } & VL & VeryLow & VeryLow & VeryLow & Moderate \\
\cline { 2 - 6 } & L & VeryLow & VeryLow & Moderate e & High \\
& M & Very Low & Moderate & High & Very High \\
\hline & H & Moderate & High & Very High & Very High \\
\hline
\end{tabular}

Using fuzzy sets, connected by logic rules, authors could define the final risk surface, and on this basis assess the risk of the planned pipeline (Fig. 6). 


\section{Model Application}

The presented model was integrated with GIS platform, so that modeling could automatically generate a result in GIS. This is especially important in strongly urbanized areas. The risk of failure occurrence in the planned gas pipelines under the influence of continuous deformations of surface was assesses.

As indicated in section 3.1, the resistance of the gas pipeline was classified as 2 category of resistance. The results of predictions of continuous deformations of terrain under the linear object allowed for determining horizontal strains under the object in a function of time. The extraction in the research area is planned to continue by the year 2063, therefore the prediction covered a 47-year period, i.e. 2016-2063. Horizontal strains up to $4.0 \mathrm{~mm} / \mathrm{m}$ are expected in the research area. The biggest deformations are expected in the years 2016-2022. The axial deformations may maximally reach $2.4[\mathrm{~mm} / \mathrm{m}]$ and occur at the 170 kilometer of the gas pipeline in 2019.

The extraction under the second part of the pipeline will be carried out by 2030 . The expected terrain deformations under the analyzed object will be smaller. Axial tensile strains along the pipeline's axis shall not exceed $1.0 \mathrm{~mm} / \mathrm{m}$.

The risk of failure occurrence was estimated on the basis of a fuzzy model, with the use of the assumed resistance of the gas pipeline, as well as predicted values of directional and principal strains under the linear object.

The risk of failure of the analyzed object was evaluated in a year's interval. Extreme values of deformation indices (in a function of time) were taken into account in the risk estimation of the pipeline damage. The final result was presented in the form of a map with risk points along the gas pipeline. The risk points defined for the years 2015-2063 assumed values from 10 to 55. The analyzed area had only one zone where a gas pipeline section could be hazarded with continuous ground deformations. This fragment of the pipeline was indicated at the boundary of the mining terrain (Fig. 7, a) zone 1). The risk points in this zone do not exceed 50 on a 120 meter section.

Continuous surface deformations, on verge of pipeline ability to withhold the strain, can be expected in that zone. The pipeline was designed taking into account time-dependent extreme deformation indices. Bearing in mind the planned production by the year 2063 in the analyzed area, this is a significant oversimplification. Therefore a more profound analysis of space-and-time distribution of risk has been performed. The results of these considerations reveal that the risk will be reduced to 40 risk points by the year 2022 (Fig. 8, a)). After 2025 it will completely disappear in zone 1 (Fig. 8, b)). The planned extraction after 2025 will have a marginal influence on continuous deformation of surface.

The surface deformations will vary, developing in the first and in the second zones in the years 2015 to 2063. Particular sections of the gas pipeline will undergo periodical strains which will completely disappear after sometime. Two points were selected in zones 1 and 2 to represent the time distribution of risk (Fig. 9). 


\section{Concluding Remarks}

The conducted research reveals that time analyses are recommended in mining-induced areas to predict possible deformations and their impact on gas networks placed in that area. Such analyses have fundamental meaning as only in this way the strain cumulation caused by mining-induced deformations can be detected. The time of operation of increased strains on the pipeline network or its fragments was also observed to be a significant parameter. Presently the compensators are usually placed uniformly over the entire pipeline length, which is unjustifiable, bearing in mind that the expected hazard is nonuniformly distributed along the pipeline, and depends on time. In the recommended approach the cost of prevention measures relating to the protection of the pipeline can be considerably reduced, without lowering the object's safety level. The compensation of axial strains should be applied only in these places where the risk of failure exceeds the boundary level, and when considerably high strains act on the pipeline.

The presented approach bases on artificial intelligence methods, allowing for the evaluation of risk of failure in a pipeline. The risk may range from 0 to 100 points, approximately corresponding to the probability of failure occurrence. In the author's method, the pipeline hazard due to the predicted horizontal (principal and axial) strains, as well as the strength of the material (pipes), duration of negative impact, significance of the object can be assessed on the basis of one figure.

The presented model has been used for evaluating the risk of a planned gas pipeline having given technological parameters. However it can be also used for simulating other technological variants of the analyzed object.

\section{Declarations}

Acknowledgment

The research reported in this paper has been supported by a grant from the National Science Centre No. 2011/01/D/ST10/06958. (corresponding author: Agnieszka Malinowska, email: amalin@agh.edu.pl)\},

\section{References}

1. Aramesh A, Montazerin N, Ahmadi A (2014) A general neural and fuzzy-neural algorithm for natural gas flow prediction in city gate stations, Energy and Buildings 72:73-79.

2. Brito AJ, de Almeida AT (2009) Multi-attribute risk assessment for risk ranking of natural gas pipelines, Reliability Engineering and System Safety 94:187-198.

3. Broniec Z, Szybka J, Tarnowski J (1998) Modeling gas pipeline on the mining areas, Zagadnienia eksploatacji maszyn 1 (1998), PAN Warszawa (in Polish).

4. Cagno E, Caron F, Mancini M, Ruggeri F (2000) Using AHP in determining the prior distributions on gas pipeline failures in a robust Bayesian approach, Reliability Engineering \& System Safety 67:275- 
284.

5. Cui X, Miao X, Wang J, Yang S, Liu H, Hu X (2000) Improved prediction of differential subsidence caused by underground mining, International Journal of Rock Mechanics \& Mining Sciences 37:615627.

6. Esayed T 2009 Fuzzy inference system for the risk assessment of liquefied natural gas carriers during loading/offloading at terminal, Applied Ocean Research 31:179-185.

7. Gao FP, Wang N, Zhao B 2013 Ultimate bearing capacity of a pipeline on clayey soils: Slip-line field solution and FEM simulation, Ocean Engineering 73:159-167, DOI: 10.1016/j.oceaneng.2013.09.003.

8. Han ZY, Weng WG (2011) Comparison study on qualitative and quantitative risk assessment methods for urban natural gas pipeline network, Journal of Hazardous Materials 189:509-518.

9. Hejmanowski R (2001) Prediction of ground deformation based on Knothe theory for mineral resources, Kraków, IGSMiE PAN (In Polish).

10. Hejmanowski R, Malinowska A, Szadziul M (2014) Spatio-temporal distribution of surface deformation in the light of the observed damages in pipelines, Przegląd Górniczy; 70:23-30 (In Polish).

11. Hotloś H, Mielcarzewicz E (2011) Warunki i ocena niezawodności działania sieci wodociągowych i kanalizacyjnych na terenach górniczych. Oficyna Wydawnicza Politechniki Wrocławskiej, Wrocław

12. Hu Y, Wen J, Li X, Wang D, Li Y (2013) A dynamic multimedia fuzzy-stochastic integrated environmental risk assessment approach for contaminated sites management, Journal of Hazardous Materials 261:522-533,http://dx.doi.org/10.1016/j.jhazmat.2013.08.009.

13. Hu Y, Wang Z, Wen J, Li Y (2016) Stochastic fuzzy environmental risk characterization of uncertainty and variability in rosk assessment: case study of polycyclic aroamtic hydrocarbons in soil at a petroleum - contaminated site in China, Journal of Hazardous Materials, In Press, DOI:10.1016/j.jhazmat.2016.05.033.

14. Jachym K, Kalisz P (2010) Failure of the gas pipeline on the mining areas. Konferencji: Bezpieczeństwo i ochrona obiektów budowlanych na terenach górniczych/konferencja naukowoszkoleniowa , Wyd. GIG, Katowice (In Polish).

15. Jamshidi A, Yazdani-Chamzini A, Yakhchali SH, Khaleghi S (2013) Developing a new fuzzy inference system for pipeline risk assessment, Journal of Loss Prevention in the Process Industries 26:197208.

16. Knothe S (1954) Profile of subsidence bowl, Archiwum Górnictwa i Hutnictwa, 1(1), Warszawa (In Polish).

17. Kopczyński A (1991) Designing gas pipeline on mining areas - guidelines. Biuro Projektów Gazownictwa Gazoprojekt (In Polish).

18. Kruse HMG, Hergarden HJAM (2010) Soil loads on Pipelines, the Dutch approach Proc. Pipeline technology conference.

19. Kwiatek J, Mokrosz R (1996) Gas pipeline on mining area. WUG, 3 (In Polish). 
20. Liang-ming P, Muhao Z, Peng J, Hui H, Mamoru IM (2016) Vertical co-current two-phase flow regime identification using fuzzy C-means clustering algorithm and Relief $\mathrm{F}$ attribute weighting technique, International Journal of Heat and Mass Transfer 95:393-404

21. Linlin L, Wie L, Laibin Z, Hong Z, Zhong L, Jinzhi S (2015) A comprehensive risk evaluation method for natural gas pipelines by combining a risk matrix with a bow-tie model, Journal of Natural Gas Science and Engineering 25:124-133.

22. Malinowska A, Hejamnowski R (2010) Building damage risk assessment on mining terrains in Poland with GIS application, International Journal of Rock Mechanics \& Mining Sciences. 47(2):238-245.

23. Malinowska AA, Hejmanowski R (2015) Fuzzy-logic assessment of failure hazard in pipelines due to mining activity, NISOLS Nagoya 372:105-109.

24. Malinowska A, Hejmanowski R, Rusek J (2016) Estimation of the parameters affecting the water pipelines on the mining terrains with a use of an adaptive fuzzy, Archives of Mining Sciences; 61(1):183-197.

25. Markowski AS, Mannan MS (2009) Fuzzy logic for piping risk assessment (pfLOPA), Journal of Loss Prevention in the Process Industries 22:921-927.

26. Marschalko M, Yilmaz I, Křístková V, Fuka M, Kubečka K, Bouchal T, Bednarik M (2012) Optimization of building site category determination in an undermined area prior to and after exhausting coal seams, International Journal of Rock Mechanics and Mining Sciences 54:9-18.

27. Mendec J, Kliszczewicz B, Wytrychowska M (1997) The terrain surface and the buildings protection against mining damages. Rules for the protection of water supply and sewerage against the influence of underground mining. Publisher Central Mining Institute. GiG, Katowice (in Polish).

28. Mokhtari K, Roberts JRCh, Wang J (2011) Application of a generic bow-tie based risk analysis framework on risk management of sea ports and offshore terminals Journal of Hazardous Materials 192:465- 475 .

29. Official Journal (2011) Polish Geological and mining law. (Dz.U. Nr 163, poz. 981) 163:981 .(In Polish)

30. Pouryoussefi SM, Zhang Y (2015) Identification of two-phase water-air flow patterns in a vertical pipe using fuzzy logic and genetic algorithm, Applied Thermal Engineering 85:195-206.

31. Qu J, Meng X, You H (2016) Multi-stage ranking of emergency technology alternatives for water source pollution accidents using a fuzzy group decision making tool, Journal of Hazardous Materials, 310: 68-81, http://dx.doi.org/10.1016/j.jhazmat.2016.01.067.

32. Rahman MA, Taniyama H (2015) Analysis of a buried pipeline subjected to fault displacement: A DEM and FEM study. Soil dynamic and earthquake engineering, 71:49-62.

33. Sroka A (1990) Selected problems in predicting influence of mining-induced ground subsidence and rock deformations. In: Proceedings 5 th International Symposium: On Deformation Measurements and Canadian Symposium on Mining Surveying and Rock Deformation; 30:237. 
34. Shahriar A, Sadiq R, Tesfamariam S (2012) Risk analysis for oil \& gas pipelines: A sustainability assessment approach using fuzzy based bow-tie analysis, Journal of Loss Prevention in the Process Industries 25:505-523.

35. Singh M, Markeset T (2009) A methodology for risk-based inspection planning of oil and gas pipes based on fuzzy logic framework. Engineering Failure Analysis, 16:2098-2113

36. Singh M, Markeset T (2004) Hybrid models for handling variability and uncertainty in probabilistic and possibilistic failure analysis of corroded pipes. Engineering Failure Analysis, 42:197-209

37. Supreme Audit Office (2012) Report on removal of mining damages caused by underground mining. Report No. 24/2012/P/11/132/LKA, www.nik.gov.pl/plik/id,3696,vp,4712.pdf (In Polish) (20.05.2016).

38. Zadeh LA (1965) Fuzzysets. Information and Control, 965, 38 (1):1-14.

\section{Figures}

\section{Figure 1}

Placement of the planned gas pipeline 


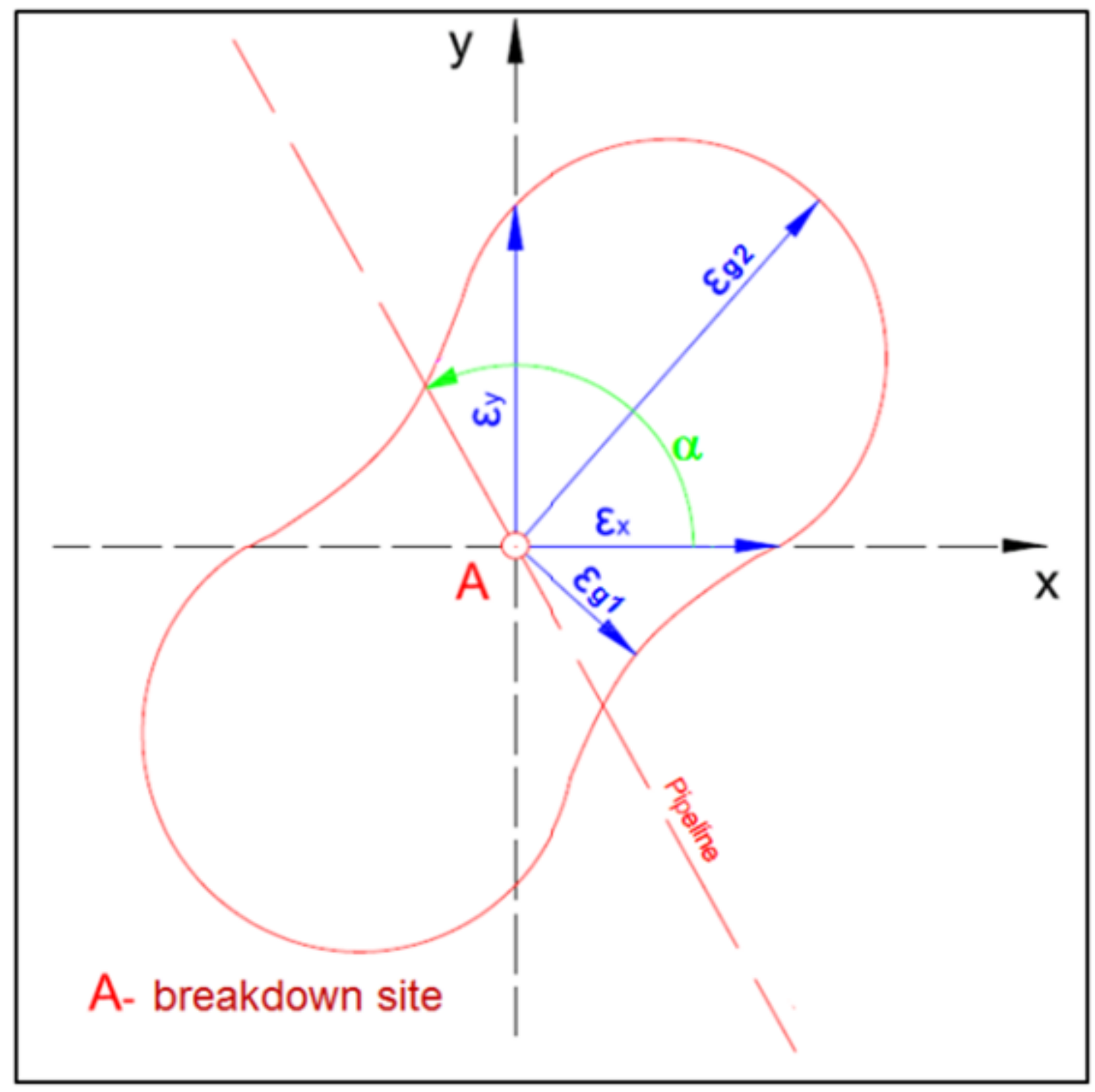

Figure 2

Distribution of axial and principal strains at a point 


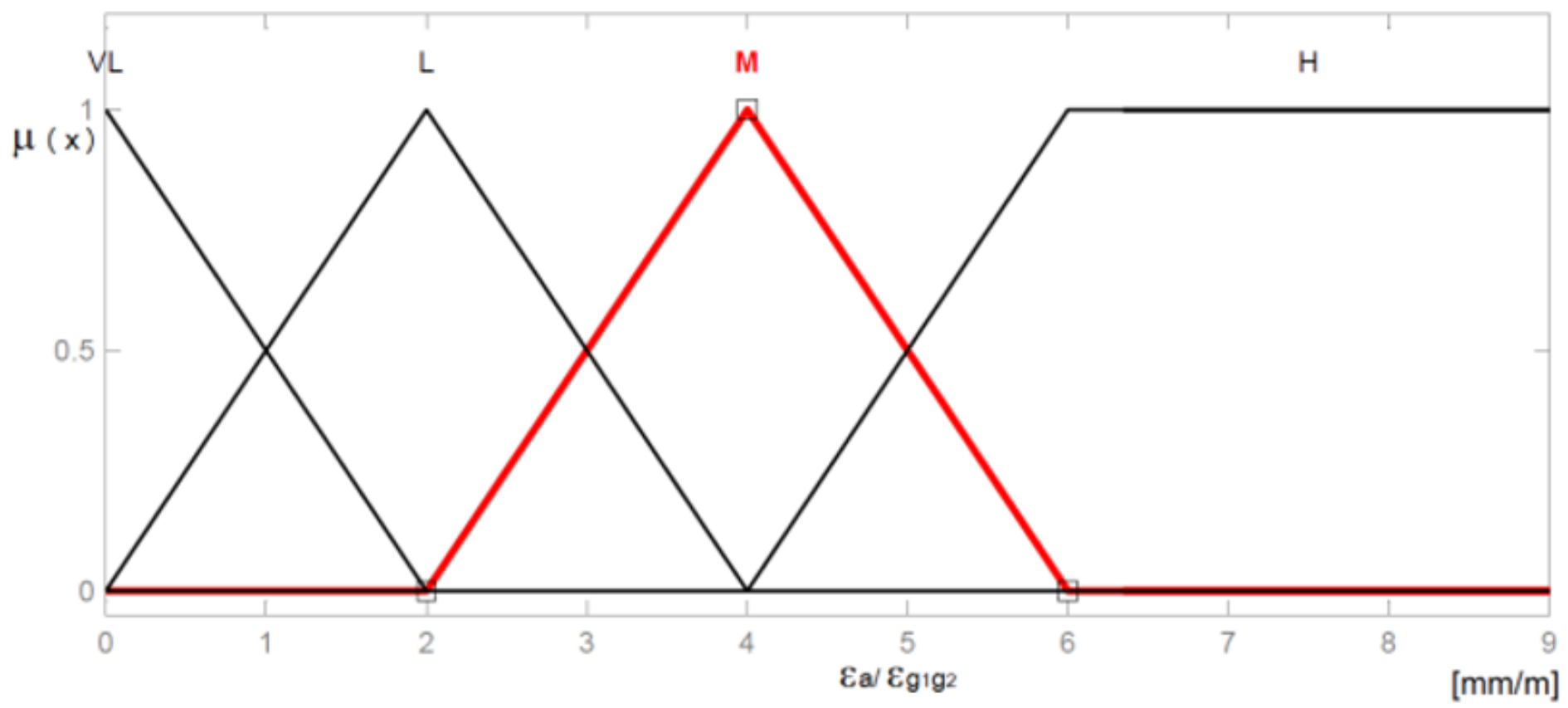

Figure 3

Membership functions for model variables, directional and principal horizontal strains

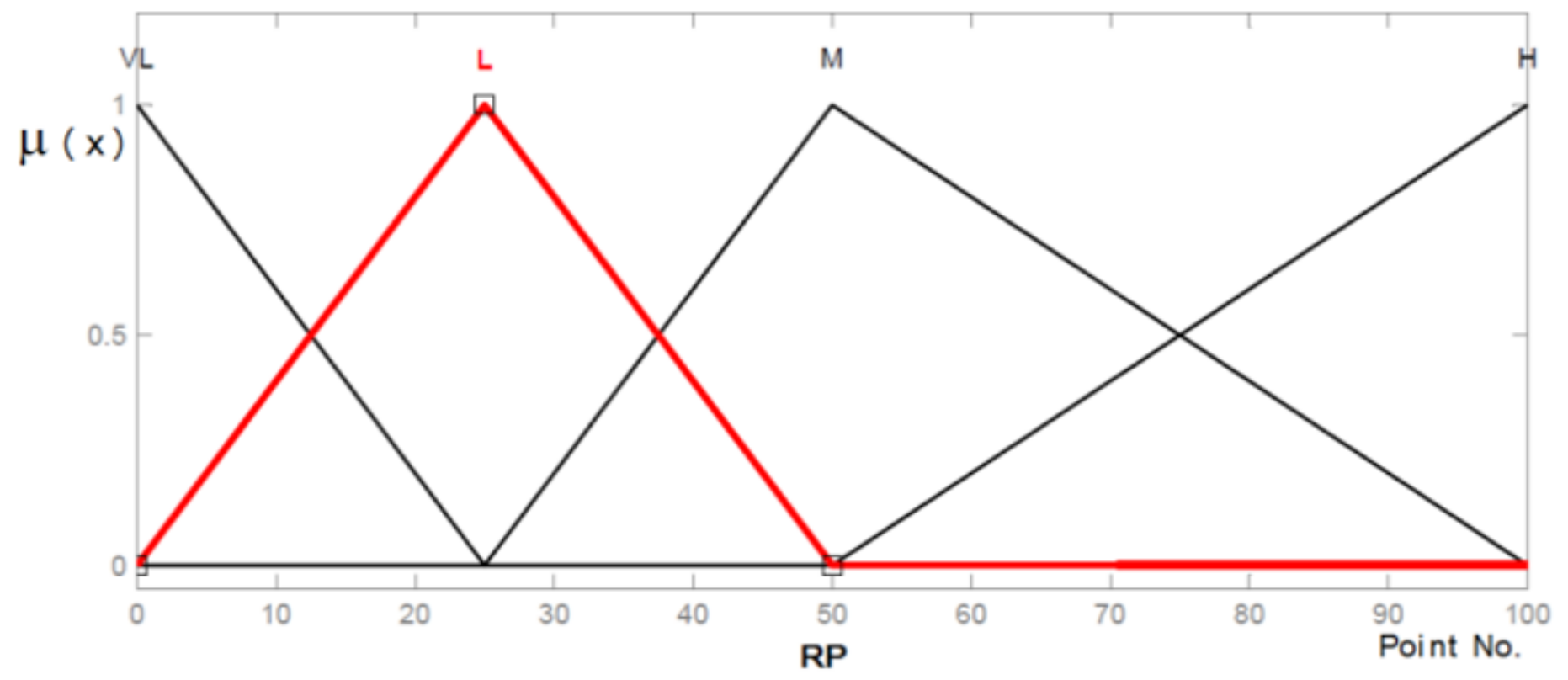

Figure 4

Membership function for gas pipeline resistance expressed in points 


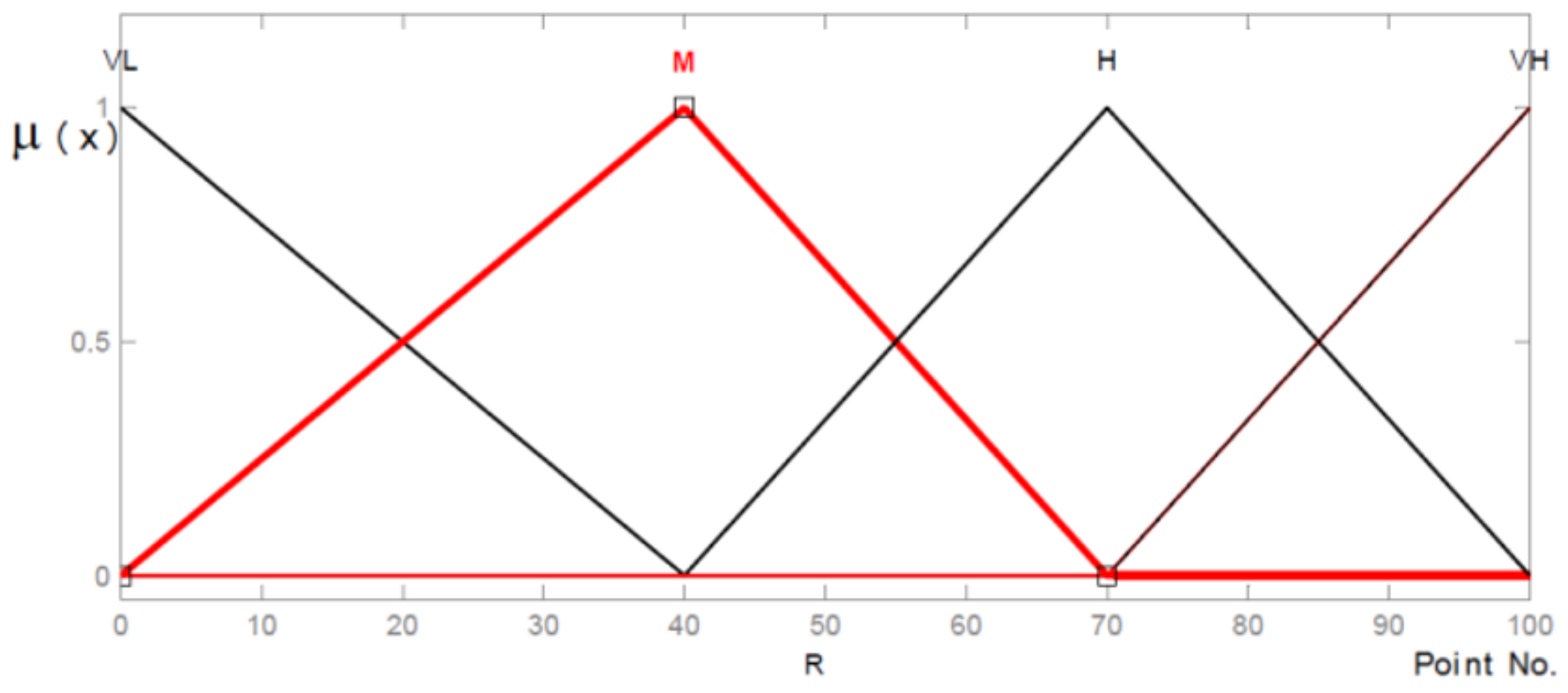

Figure 5

Risk of damage of a linear object

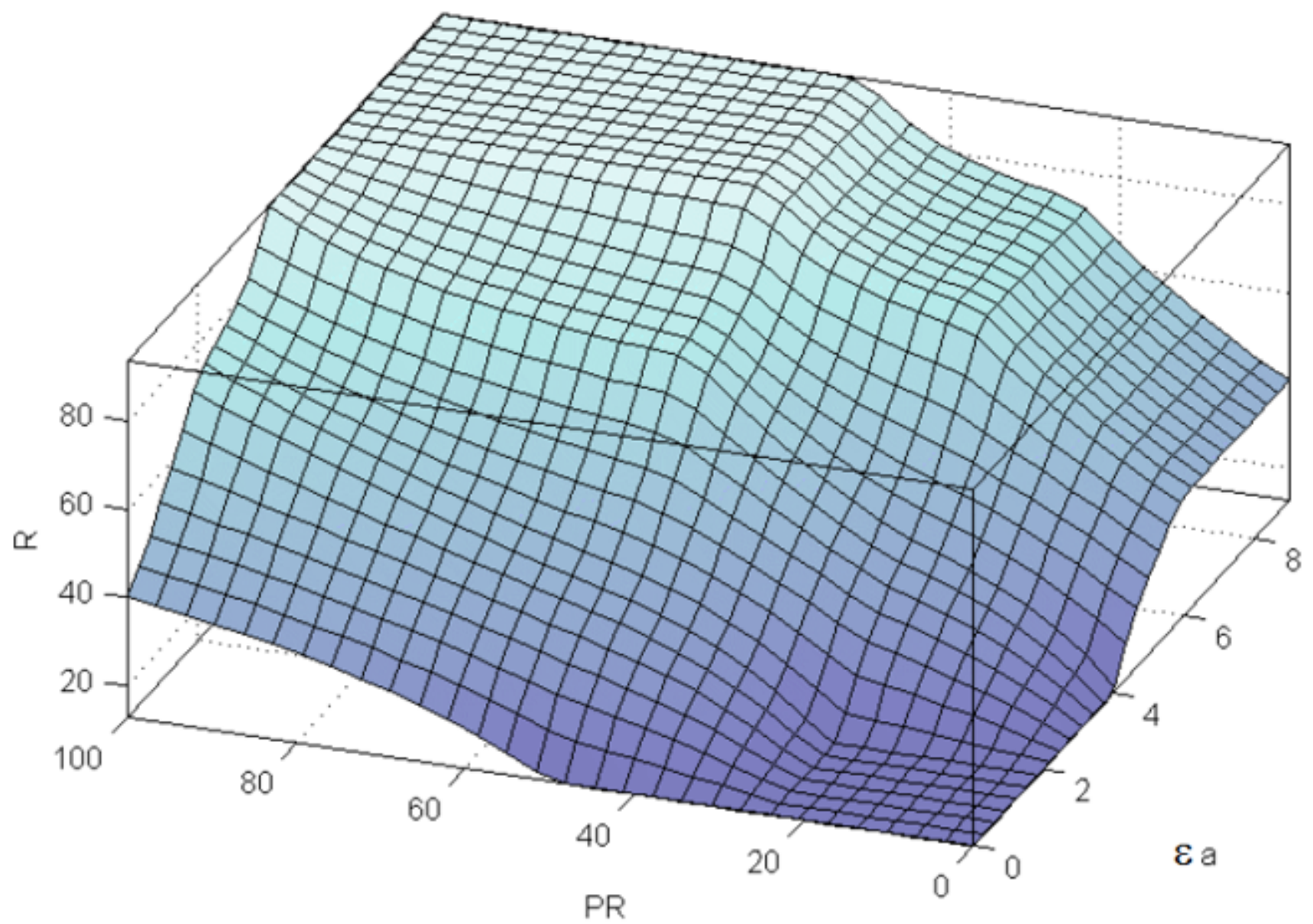

Figure 6 
Risk surface of a gas pipeline depending on its strength and axial horizontal strains

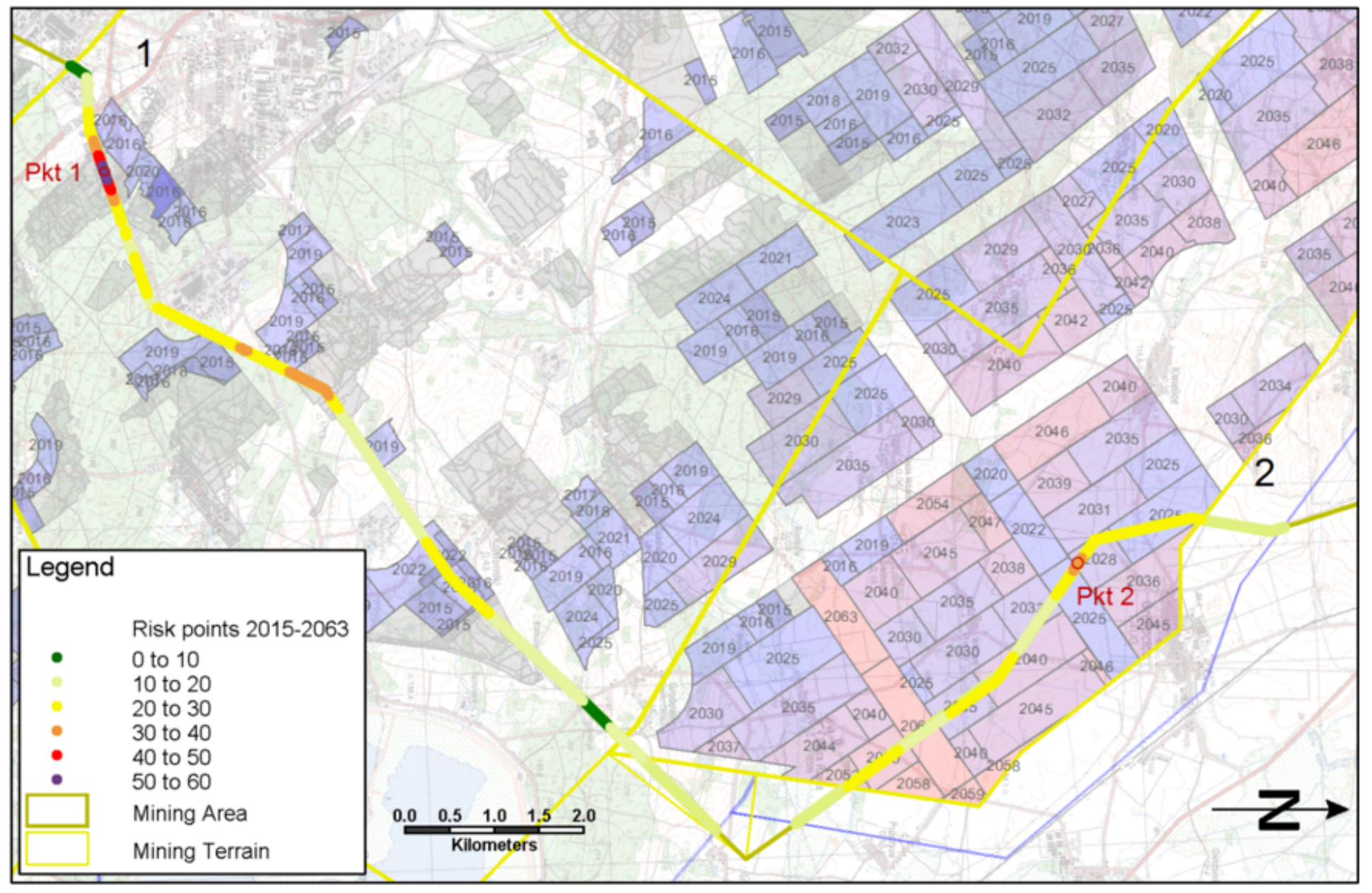

Figure 7

Evaluation of risk of pipeline failure with fuzzy model 

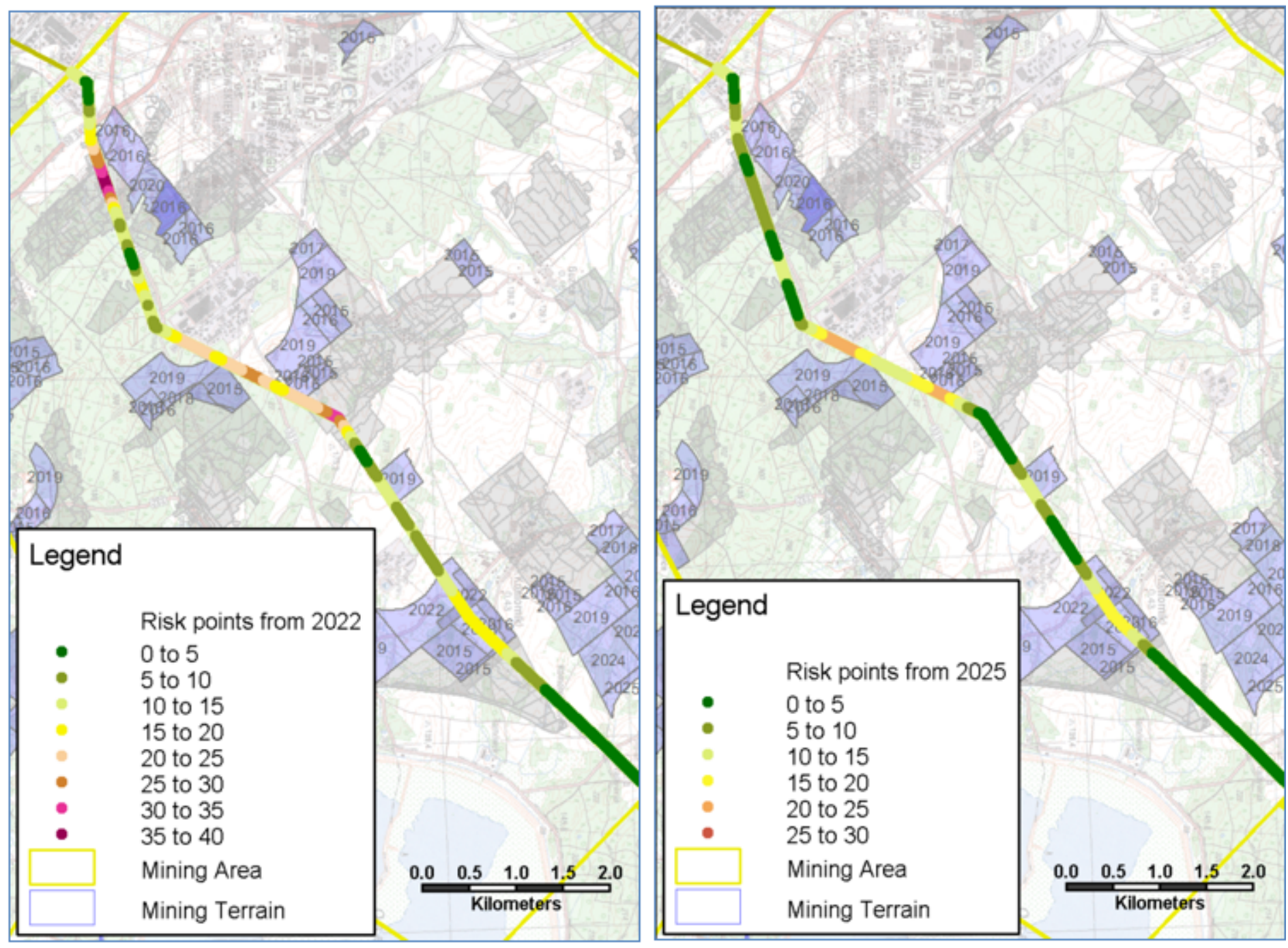

a)

b)

Figure 8

Time-and-space risk analysis of pipelines with fuzzy model after 2022 a) and after 2025 b) 


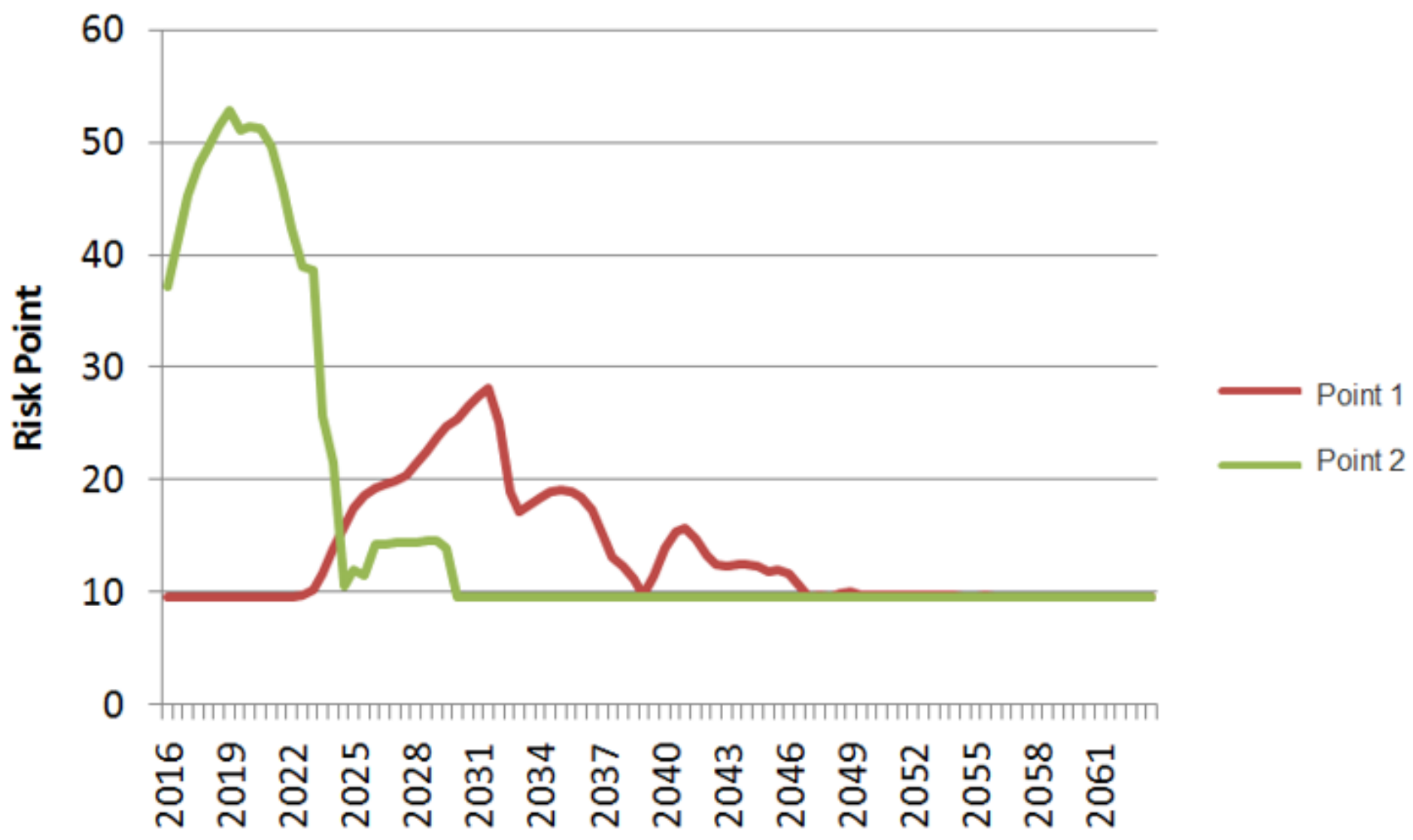

Figure 9

Distribution of risk in time for selected points along the pipeline 